Article

\title{
Fostering Responsible Innovation through Stakeholder Engagement: Case Study of North Carolina Sweetpotato Stakeholders
}

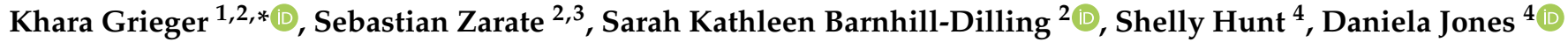 \\ and Jennifer Kuzma ${ }^{2,5}$
}

1 Department of Applied Ecology, North Carolina State University, Raleigh, NC 27695-7617, USA

2 Genetic Engineering and Society Center, North Carolina State University, Raleigh, NC 27695-7565, USA; jszarate@ncsu.edu (S.Z.); skbarnhi@ncsu.edu (S.K.B.-D.); jkuzma@ncsu.edu (J.K.)

3 Department of Forestry and Environmental Resources, North Carolina State University, Raleigh, NC 27695-8008, USA

4 Department of Biological and Agricultural Engineering, North Carolina State University, Raleigh, NC 27695-7625, USA; rlransom@ncsu.edu (S.H.); dsjones5@ncsu.edu (D.J.)

5 School of Public and International Affairs, North Carolina State University, Raleigh, NC 27695-8102, USA

* Correspondence: kdgriege@ncsu.edu

check for updates

Citation: Grieger, K.; Zarate, S.; Barnhill-Dilling, S.K.; Hunt, S.; Jones, D.; Kuzma, J. Fostering Responsible Innovation through Stakeholder Engagement: Case Study of North Carolina Sweetpotato Stakeholders. Sustainability 2022, 14, 2274. https:// doi.org/10.3390/su14042274

Academic Editors: Andrew Kliskey, Daniel Cronan and David Griffith

Received: 13 December 2021

Accepted: 15 February 2022

Published: 17 February 2022

Publisher's Note: MDPI stays neutral with regard to jurisdictional claims in published maps and institutional affiliations.

Copyright: (c) 2022 by the authors. Licensee MDPI, Basel, Switzerland. This article is an open access article distributed under the terms and conditions of the Creative Commons Attribution (CC BY) license (https:/ / creativecommons.org/licenses/by/ $4.0 /)$.

\begin{abstract}
Stakeholder and community engagement are critical for the successful development of new technologies that aim to be integrated into sustainable agriculture systems. This study reports on an approach used to engage stakeholders within the sweetpotato community in North Carolina to understand their preferences, needs, and concerns as they relate to a new sensing and diagnostic platform. This work also demonstrates an example of real-time technology assessment that also fosters responsible innovation through inclusivity and responsiveness. Through the conduction of 29 interviews with sweetpotato stakeholders in North Carolina, we found that participants found the most value in detecting external sweetpotato characteristics, as well as the ability to use or connect to a smartphone that can be used in field. They also found value in including environmental parameters and having a Spanish language module. Most participants indicated that they were comfortable with sharing data as long as it benefited the greater North Carolina sweetpotato industry, and were concerned with sharing these data with "outside" competitors. We also observed differences and variations between stakeholder groups. Overall, this work demonstrates a relatively simple, low-cost approach to eliciting stakeholder needs within a local agricultural context to improve sustainability, an approach that could be leveraged and transferred to other local agrifood systems.
\end{abstract}

Keywords: responsible innovation; stakeholder engagement; sustainability; sweetpotatoes

\section{Introduction}

It is increasingly recognized that stakeholder and community engagement are essential to developing new food and agriculture technologies [1]. Benefits of stakeholder engagement within agrifood technology development include responding to stakeholder and community member needs, incorporating diverse perspectives, improving transparency, co-creating knowledge and associated outcomes, improving technology adoption rates, and developing more sustainable agrifood technology solutions [1,2]. In this work, we define stakeholders as individuals who are directly impacted by a project and/or generated outcome(s), often with decision-making abilities, and community members as individuals whose values and priorities need to be considered but do not have direct decision-making abilities [1]. Current scholarship in sustainability and innovation also recognize the dynamic and integral connections between social, technical, and ecological processes [2]. While traditional agrifood technology development has had relatively limited stakeholder engagement and outreach initiatives, due to, for example, time and/or cost constraints, and 
a desire to maintain control over innovation processes, it is becoming more recognized that the benefits of having more open and inclusive innovation practices in agrifood systems can be advantageous in the long term [3].

Stakeholder engagement to inform agrifood technology development and innovation can occur through a range of actions and practices $[4,5]$. On one end of this spectrum are engagement activities that have a primary purpose of outreach and knowledge dissemination from researchers to stakeholders or the public, such as the use of exhibits at science museums or posters at science fairs. Other engagement activities aim to understand stakeholder perceptions and views, often through surveys, focus groups, or interviews. On the other end of this spectrum are engagement activities that aim to closely engage or collaborate with stakeholders to co-develop or co-create knowledge or solutions [4,5]. In a broader context, and as a way to leverage stakeholder engagement to inform technology innovation processes, technology assessment is one approach that can help inform, shape, and prioritize technology policies and innovation strategies [4]. Through deliberate evaluations of potential societal, economic, and environmental implications of new technologies, technology assessment aims to provide foresight and potential policy implications in early stages of technology development. For example, real-time technology assessment [5] and constructive technology assessment [6] are two forms of technology assessment that have well exemplified the importance of engaging actors in early stages of technological development. In these assessments, stakeholders are engaged through deliberative processes to better understand their perceptions, views, as well as needs and/or concerns, in order to evaluate and inform subsequent technology development while also increasing transparency and accountability [6,7].

Building off these fields, responsible innovation (RI) has emerged over the past decade with foundations in ethical, legal, and societal aspects of emerging technologies, upstream technology assessment, real-time technology assessment, and participatory technology assessment [8]. Like these prior frameworks, RI includes a call for upstream engagement of publics and stakeholders in technological development and deployment through its principles [9]. For example, the RI principle of inclusion suggests stakeholders and publics be an integral part of conversations about early stages of technology R\&D [9]. The principle of anticipation engages stakeholders and publics in examining the potential downstream consequences of technology, and the principle of responsiveness obliges developers to incorporate their input to affect the course of technology development $[9,10]$. von Schomberg [11], p. 9, also describes RI as a "transparent, interactive process by which societal actors and innovators become mutually responsive to each other with a view on the (ethical) acceptability, sustainability and societal desirability of the innovation process and its marketable products." Further, several frameworks of RI also incorporate the concept of sustainability, given that sustainability has not only environmental but also social, cultural, and economic dimensions of care [10]. As described more below, our work on engaging agricultural stakeholders was inspired by RI principles of inclusion, anticipation, and responsiveness, as well as desires to ensure sustainable development of the technology through inclusion of stakeholders' perspectives within a specific case study.

Given that food and agriculture systems tend to be contextually-based with local actors and conditions often playing significant roles, stakeholder engagement within agrifood systems need to be tailored to account for these contextual circumstances [1]. This is because agricultural research on farming systems has revealed vast degrees of diversity and complexity of farming practices. In response, farmers' participation in agricultural research has also become a focal point of many interventions in agricultural systems [12], where they often play key roles in conducting agricultural research [13]. These studies typically rely on semi-structured interviews with farmers and other key stakeholders as well as content analysis of policy documents, in order to understand and illuminate key themes and concepts within agrifood system contexts.

For the previously mentioned reasons related to engaging agricultural stakeholders in research and technology adoption, we developed a customized approach to engage 
stakeholders within the context of the local sweetpotato community in North Carolina. The sweetpotato industry was selected for this work because North Carolina produces approximately half of all sweetpotatoes grown in the U.S. [14], contributing an average of \$330 million annually since 2014 to the state's economy. Sweetpotato also ranks globally as the seventh most important food crop, and as the third most important root crop [15]. Today, consumers increasingly prefer sweetpotatoes that are symmetrical and uniform in size for various reasons (e.g., easiness to peel) [16], and in response, there are different grades of sweetpotatoes, such as U.S. No. 1 (i.e., 3-9 inches in length, weight $\geq 20$ ounces, 13/4-31/4 inches in diameter) [17]. Growers therefore aim to optimize their produce to meet such shape and size standards.

Our stakeholder engagement work was led by the authors of this paper and was a part of a larger project funded by North Carolina University, called Sweet-APPS (sweetpotatoanalytics.com; Accessed on 16 February 2022), that aims to develop new sensing technologies to address grower and consumer needs (e.g., to better estimate the size and shape of sweetpotatoes). Sweet-APPS is also developing an integrative data platform to better evaluate factors that influence yield (e.g., size, shape, environmental conditions, agricultural cultural practices). The Sweet-APPS project is, in fact, the first of its kind to develop new technologies for the sweetpotato industry with a focus on improved sensing and grading technologies with an advanced data analytics platform. Because the research team is well aware of the need to couple agrifood technology development together with stakeholder perceptions and needs, the Sweet-APPS project deliberately developed and designed an iterative stakeholder engagement process to better align with stakeholder needs and preferences. Further, Sweet-APPS also aims to help improve sustainability practices, by reducing food waste attributed to growing, harvesting, and processing sweetpotatoes that may not meet consumer preferences. In fact, we know that approximately one-third of edible food that is produced is wasted, contributing to $10 \%$ of global greenhouse gas emissions according to 2010-2016 estimates [18,19]. Further, global food waste from root and tuber crops is $45 \%$ per year, which contributes not only emissions but also leads to ineffective land use [18,19]. In other words, by engaging stakeholders in early stages of technology development across the sweetpotato value chain, stakeholder needs can be more easily met, food waste can be reduced, and social and environmental sustainability within the sweetpotato industry can be improved (Figure 1).

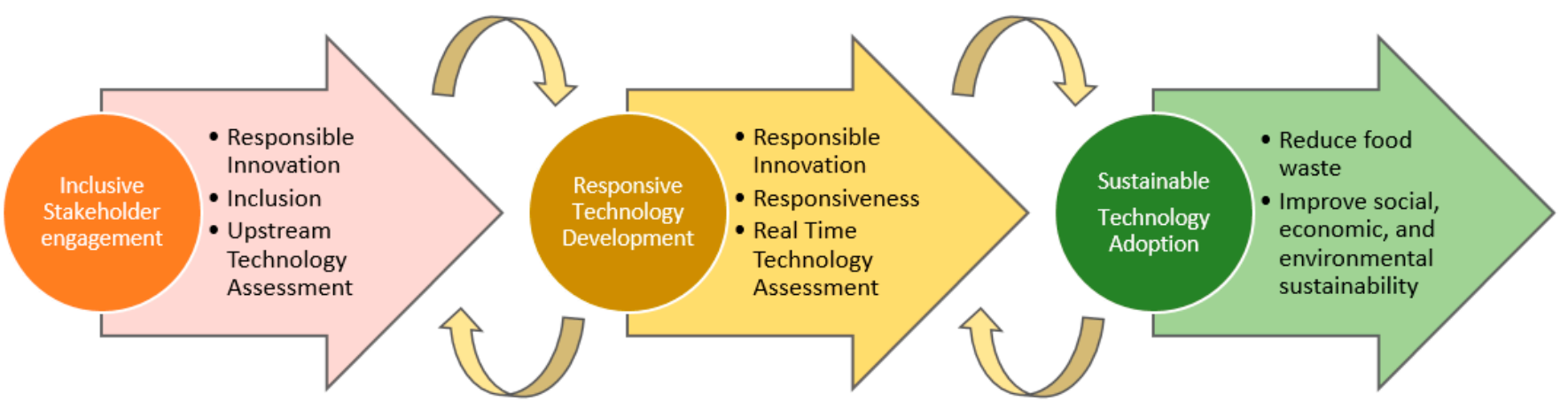

Figure 1. Interdisciplinary connections between stakeholder engagement, responsible innovation, technology adoption, and sustainability within agrifood systems.

The Sweet-APPS project developed a tailored approach to engage a range of stakeholders within the project's technology development and innovation processes. The benefits of engaging stakeholders in this project include developing a new sensing and data analytics platform in a way that responds to stakeholder needs and preferences in complex agricultural systems to meet consumer desires while also improving sustainability goals (e.g., less waste in production, harvesting, processing) and adhering to core principles of RI (Figure 1). This paper therefore aims to present (i) the Sweet-APPS approach to engage local sweetpotato stakeholders as an example of real-time technology assessment that feeds 
back to the research team and responsivity as a principle of RI; (ii) main findings, in terms of stakeholder needs, preferences, and concerns of developing a new sensing and data analytics platform; and (iii) key lessons learned from our approach and recommendations for engaging stakeholders in other agrifood systems.

\section{Methods}

In this study, we conducted individual interviews with stakeholders involved in the North Carolina sweetpotato value chain in order to understand their perceptions, needs, and concerns as they relate to sensing technology implementation and data-driven decision tools. Sensing technologies include the implementation of optical sensors (i.e., cameras) to detect and measure physical characteristics of sweetpotatoes such as size, shape, surface defects, internal defects, and other traits. Data-driven decision tools refer to a set of data analytics tools and approaches (e.g., machine learning) to understand the factors, such as growing conditions, that affect sweetpotato characteristics and yield, including quantity and quality. The goal of the stakeholder interviews was to first understand their preferences, needs, and concerns related to technologies being developed in Sweet-APPS, and then be responsive to these needs within technology development stages.

An overview of this process is shown in Figure 2, and more details are included below.
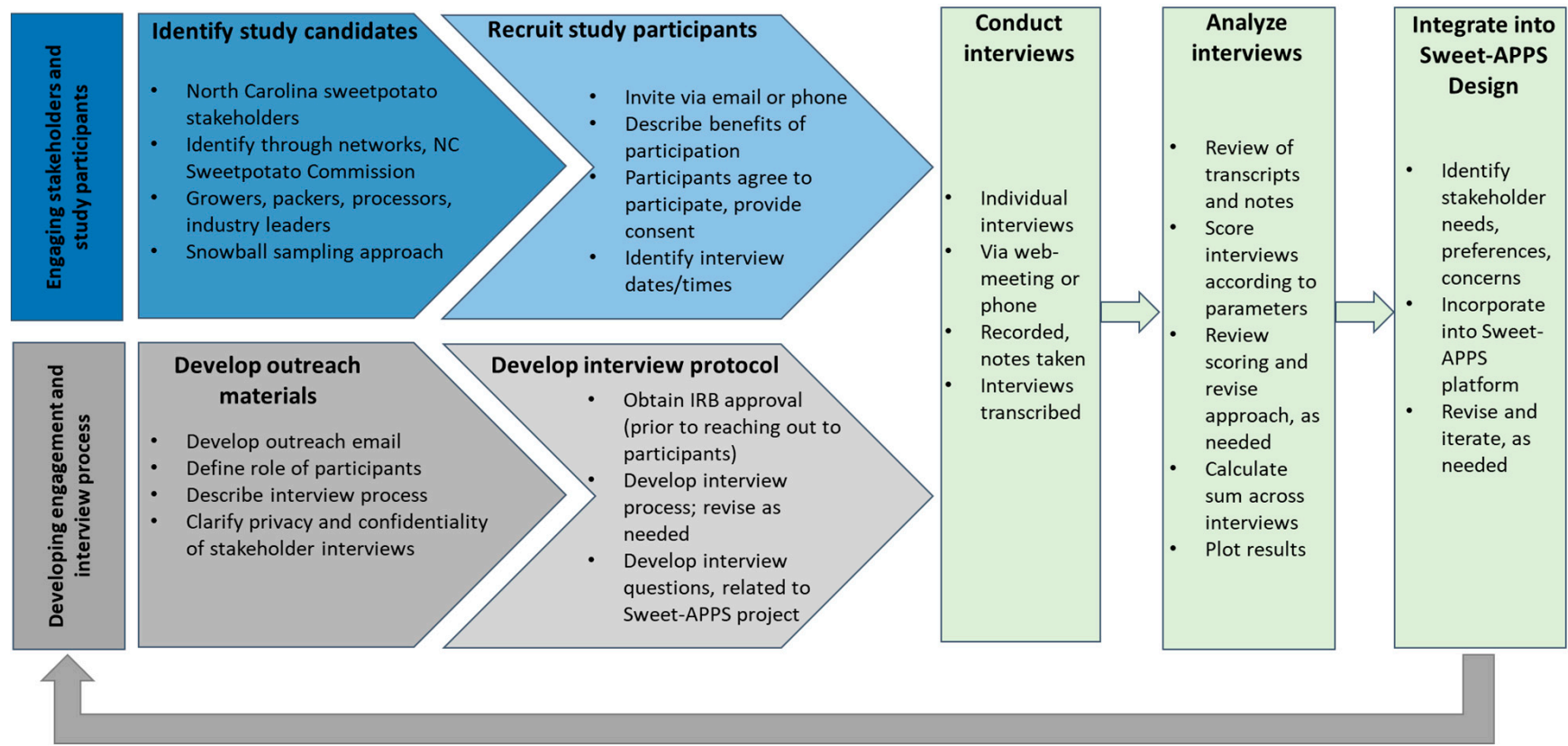

Figure 2. Overview of process to engage stakeholders in Sweet-APPS.

\subsection{Stakeholder Participant Identification and Recruitment}

We aimed to include study participants from a range of sectors associated with North Carolina's sweetpotato value chain, including growers, packers, processors, farmers, and industry leaders. Participants were identified through a variety of mechanisms. First, we identified participants through connections with the North Carolina Sweetpotato Commission, which is a nonprofit organization comprised of more than 400 sweetpotato growers, packers, processors, and business leaders associated with the North Carolina sweetpotato community. The Commission provided recommendations on a variety of sweetpotato stakeholders that may be interested in participating in the study. We also identified study participants through a snowball sampling approach, in which participants provided suggestions and recommendations for other individuals who may be relevant and interested in partaking in the study. Finally, we identified participants through the research team's connections with the larger North Carolina sweetpotato community, given that NC State has a large sweetpotato research and extension program. To participate in the study, stake- 
holders needed to be involved in a sector related to the sweetpotato industry in North Carolina and have access to a phone or computer. Participants were also required to review and sign a consent form prior to engaging with the project.

In total, we identified 77 potential study participants and invited them to partake in the Sweet-APPS study via email or phone. IRB approval was obtained from the PI's institution (NC State University, IRB protocol 22347) prior to reaching out to potential participants. A total of 29 stakeholders agreed to participate in the study (i.e., $38 \%$ response rate). Identified benefits to study participants included having the opportunity to provide feedback and stakeholder perceptions regarding a new sensing and data analytic platform, with the overall goal of helping to improve the sweetpotato industry in North Carolina.

\subsection{Outreach Materials and Interview Protocol}

After identifying study participants, we developed outreach materials. These materials included an initial email sent to potential study participants, a follow-up email for participants who expressed interest, a consent form, and an overview of the activities completed by study participants. For those who indicated they were interested in participating in the study, we identified a range of suitable dates/times for the interviews to be conducted. In this outreach process, study participants were also sent information about the Sweet-APPS project, their role in the study as interviewees, details of the interview including a list of questions, and the fact that the interviews would be recorded and notes taken. We also notified participants that all interviews and associated notes would remain confidential, only de-identified data would be used in generated results, and at no point would participant name or company name be used (per NC State IRB protocol number 22347).

Next, we developed the interview protocol and a list of questions. The interview questions included 23 semi-structured questions related to three areas: (1) scanning and imaging technology, (2) user interface, and (3) data and user privacy, based on the needs of the Sweet-APPS project (see Supplementary Information, SI, for more details). Table 1 provides a shortened list of questions posed to study participants, and the SI provides a complete description of the interview protocol and associated questions. In the interview process, we provided the interviewees with a definition of a diagnostic sensing and data platform, user interface, and background information on how the project intends to use and store data relevant for questions on perceptions of data and privacy concerns (SI). As detailed in the SI, we defined a diagnostic sensing and data platform as an integrated platform that relies on sensing to detect external and internal features of sweetpotatoes, as well as data science and analytic capabilities to help stakeholders make informed management decisions to reduce waste, maximize their socioeconomic wellbeing, and increase sustainability. We also defined user interface as the means by which a stakeholder or user and a computer system interact, such as a computer program, model, or app. We also provided other definitions of terms used in the interviews, including a cloud data service provider and what was meant by aggregated data and information (see SI for details).

The 23 interview questions corresponded to 20 parameters being investigated in the Sweet-APPS project, which were also used to analyze the interviews. The interview questions were sent to participants one week prior to the conduction of the interviews. All interview questions are included in the SI. 
Table 1. Semi-structured interview questions posed to study participants. $\mathrm{SP}=$ sweetpotato; $\mathrm{EF}=$ environmental factor; $\mathrm{UI}=$ user interface; $\mathrm{DP}=$ data and privacy; $\mathrm{OE}=$ open-ended question.

\begin{tabular}{|c|c|c|}
\hline Theme & Interview Question & Parameter Investigated \\
\hline \multirow{9}{*}{$\begin{array}{l}\text { Scanning and } \\
\text { imaging } \\
\text { technology }\end{array}$} & $\begin{array}{l}\text { 1. What are some production issues or storage problems that } \\
\text { you think could be addressed with a new diagnostic sensing } \\
\text { and data platform? }\end{array}$ & $\mathrm{OE}$ \\
\hline & $\begin{array}{l}\text { 2. On a scale from not important to very important, how } \\
\text { important do you think it is to estimate SP yields for their: Size? } \\
\text { Shape? Color? Surface defects? }\end{array}$ & $\begin{array}{l}\text { 1. SP-Size(break/)2. SP-Shape }(\text { break/)3. } \\
\text { SP-Color(break/)4. SP-Surface defects }\end{array}$ \\
\hline & $\begin{array}{l}\text { 3. Would you like to elaborate on the importance of any of these } \\
\text { or other SP characteristics? }\end{array}$ & 1-4. SP-Size, shape, color, surface defects \\
\hline & $\begin{array}{l}\text { 4. Are there particular attributes or features you would like to } \\
\text { see included in an imaging, diagnosis, and analysis framework? }\end{array}$ & $\mathrm{OE}$ \\
\hline & $\begin{array}{l}\text { 5. Do you think the platform should address chemical or } \\
\text { physical indicators of internal produce damage (such as internal } \\
\text { necrosis, rot, or insect damage)? Why or why not? }\end{array}$ & 5. SP-Internal defects \\
\hline & $\begin{array}{l}\text { 6. Our team was also interested in including deep-tissue quality } \\
\text { that are superior to X-ray scanners, to detect internal } \\
\text { metabolites, absorption, and cellular distributions. Would this } \\
\text { be of interest to you? Why or why not? }\end{array}$ & 6. SP-Deep tissue \\
\hline & $\begin{array}{l}\text { 7. Do you think it is important to quantify environmental } \\
\text { factors, such as temperature, rainfall, soil moisture, pest } \\
\text { pressure, when estimating yield in the field? Why or why not? }\end{array}$ & $\begin{array}{l}\text { 7. EF-Rainfall(break/)8. EF-Soil } \\
\text { moisture(break/)9. EF-Pest } \\
\text { pressure(break/)10. EF-Temperature }\end{array}$ \\
\hline & $\begin{array}{l}\text { 8. Can you rank these environmental parameters in order of } \\
\text { priority, from most important to least important? }\end{array}$ & $\begin{array}{l}\text { 7-10. EF-Rainfall, soil moisture, pest } \\
\text { pressure, temperature }\end{array}$ \\
\hline & $\begin{array}{l}\text { 9. Are there any other characteristics of SP that are important to } \\
\text { quantify? If so, what are they? }\end{array}$ & $\begin{array}{l}\text { OE; Based on interviewee responses- }-11 . \\
\text { Prod. Practices }\end{array}$ \\
\hline \multirow{3}{*}{ User interface } & $\begin{array}{l}\text { 10. Do you think it would be useful (for you or other } \\
\text { stakeholders) to have the ability to use or connect to a smart } \\
\text { phone rather than only using a desktop or laptop computer? } \\
\text { Why or why not? }\end{array}$ & 12. UI-Smart phone \\
\hline & $\begin{array}{l}\text { 11. Do you think a Spanish module would be useful as well? } \\
\text { Why or why not? }\end{array}$ & 13. UI-Spanish \\
\hline & $\begin{array}{l}\text { 12. Are there any other features on the user interface that you } \\
\text { think would be helpful for stakeholders? If so, what are they? }\end{array}$ & $\mathrm{OE}$ \\
\hline \multirow{5}{*}{$\begin{array}{l}\text { Data and user } \\
\text { privacy }\end{array}$} & $\begin{array}{l}\text { 13. Do you have any questions about storing your data on a } \\
\text { cloud? If so, what are they? }\end{array}$ & $\mathrm{OE}$ \\
\hline & $\begin{array}{l}\text { 14. Do you think it is important to have privacy and data } \\
\text { protection regarding SP shape, size, color, and surface defects } \\
\text { when considering a sorting system? Why or why not? }\end{array}$ & 14. DP-SP key attributes \\
\hline & $\begin{array}{l}\text { 15. Do you think it is important to have privacy and data } \\
\text { protection for environmental parameters, such as temperature, } \\
\text { rainfall, soil moisture, and pest pressure? Why or why not? }\end{array}$ & 15. DP-Environmental parameters \\
\hline & $\begin{array}{l}\text { 16. Do you think it is important to have privacy and data } \\
\text { protection for production practices or inputs such as application } \\
\text { of fertilizers, pesticides, harvest time, or other factors? Why or } \\
\text { why not? }\end{array}$ & 16. DP-Production practices \\
\hline & $\begin{array}{l}\text { 17. Do you think it is important to have privacy and data } \\
\text { protection on any licensed algorithms generated by this project } \\
\text { and developed by the NC State Sweet-APPS team? Why or } \\
\text { why not? }\end{array}$ & 17. DP-Algorithms \\
\hline
\end{tabular}


Table 1. Cont.

\begin{tabular}{lll}
\hline Theme & \multicolumn{1}{c}{ Interview Question } & \multicolumn{1}{c}{ Parameter Investigated } \\
\hline $\begin{array}{l}\text { 18. Do you have any questions or concerns about de-identifying } \\
\text { and aggregating your data and information with others } \\
\text { stakeholders? If yes, what are they? }\end{array}$ & 18. DP-Aggregating data \\
\hline $\begin{array}{l}\text { 19. On a scale from not at all comfortable to completely } \\
\text { comfortable, how comfortable are you with sharing your data } \\
\text { with other stakeholders? }\end{array}$ & 19. DP-Comfort sharing \\
$\begin{array}{l}\text { 20. We are also exploring an option of stakeholders being able } \\
\text { to only share output analytics with other stakeholders rather } \\
\text { than sharing their own, raw data. Would that be of interest to } \\
\text { you? Why or why not? }\end{array}$ & 19. DP-Comfort sharing \\
$\begin{array}{l}\text { 21. Are there certain data points or pieces of information that } \\
\text { you are most concerned or least concerned about sharing? If so, } \\
\text { what are they? }\end{array}$ & 20. DP-Concerned Access \\
$\begin{array}{l}\text { 22. Who are you most concerned about in regard to accessing } \\
\text { your data? Why? }\end{array}$ & 20. DP-Concerned Access \\
$\begin{array}{l}\text { 23. Are there any other issues or thoughts that we haven't } \\
\text { discussed that you think will be important in regard to } \\
\text { improving your profitability, or any topics related to data, } \\
\text { privacy, and users? If so, what are they? }\end{array}$ & OE \\
\hline
\end{tabular}

\subsection{Stakeholder Interviews}

Stakeholder interviews were conducted using a virtual meeting platform (Zoom) or via phone between December 2020 and June 2021. All interviews generally lasted between 30 and $60 \mathrm{~min}$. All interviews were audio-recorded and transcribed, and extensive notes were taken for subsequent analysis. Each interview was conducted with at least two members of the research team-one team member would lead and conduct the interview, while the other team member would take notes. All interviews were confidential and only de-identified data were used in analysis and reporting. The interviews followed a semistructured interview protocol (Table 1; see SI for full details).

\subsection{Analysis of Results}

After the interviews were conducted, we reviewed the interview transcripts and notes and qualitatively assessed whether each of the 20 Sweet-APPS parameters were of value or importance to each of the 29 interviewees. As shown in Table 1, there were 20 parameters related to the Sweet-APPS platform that were investigated through the interviews with stakeholder participants, aligning with three main interview themes (scanning and imaging technology, user interface, and data and user privacy). After reviewing the transcripts and notes for each of the 29 interviews, we scored the interviews according to the 20 parameters, using a value of 1 to indicate parameters that were deemed of importance according to participants and a 0 for parameters that were deemed unimportant or were not mentioned by the interviewees. Based on this scoring of individual interviews, we then calculated a sum across all 29 interviews according to each of the parameters and plotted the results using a bar graph. We used this semi-quantitative approach to analyze the interviews in order to perform an initial screening of parameters deemed of importance by study participants. We also analyzed the interview transcripts for exemplary quotes to highlight parameters and associated issues that were important to the stakeholders. More in-depth qualitative analyses will be conducted in follow-up work through the use of qualitative coding software to code interview transcripts related to key topics of inquiry. 


\section{Results}

In this section, we first report on the distribution of study participants across stakeholder sectors. Then, we report on participant views of the investigated parameters according to their perceived importance or value. Here, we find value in distinguishing between participants' views of the features and attributes of the Sweet-APPS platform as a scanning and imaging technology (parameters \#1-13) and views of data and privacy concerns (parameters \#14-20). We then discuss these findings as well as the potential advantages and limitations of our approach in Section 4.

\subsection{Distribution of Stakeholder Participants across the Supply Chain}

The distribution of the 29 participants across sectors were categorized as follows: growers with packing lines $(n=9,31 \%)$, growers without packing lines $(n=6,21 \%)$, industry and leadership ( $n=10,34 \%)$, and supply chain stakeholders (i.e., processors, buyers, and shippers) ( $n=4,14 \%)$ (Figure 3). Stakeholders identified as "growers" are individuals who are in charge of growing and harvesting sweetpotatoes with the purpose of selling them. Some growers have access to or own packing lines (termed as "growers with packing lines"). Growers with packing lines also have the ability to pack sweetpotatoes for shipping and distribution to retailers. "Growers without packing lines" are individuals who grow sweetpotatoes but do not perform packing within their own operations. "Industry and leadership" refers to individuals involved in the management and leadership of sweetpotato industries, some of whom were growers or have interacted with growers, and "supply chain stakeholders" refer to individuals who are involved in buying from packers, processing, shipping, and/or distributing sweetpotatoes, and are not associated with growing and packing operations.

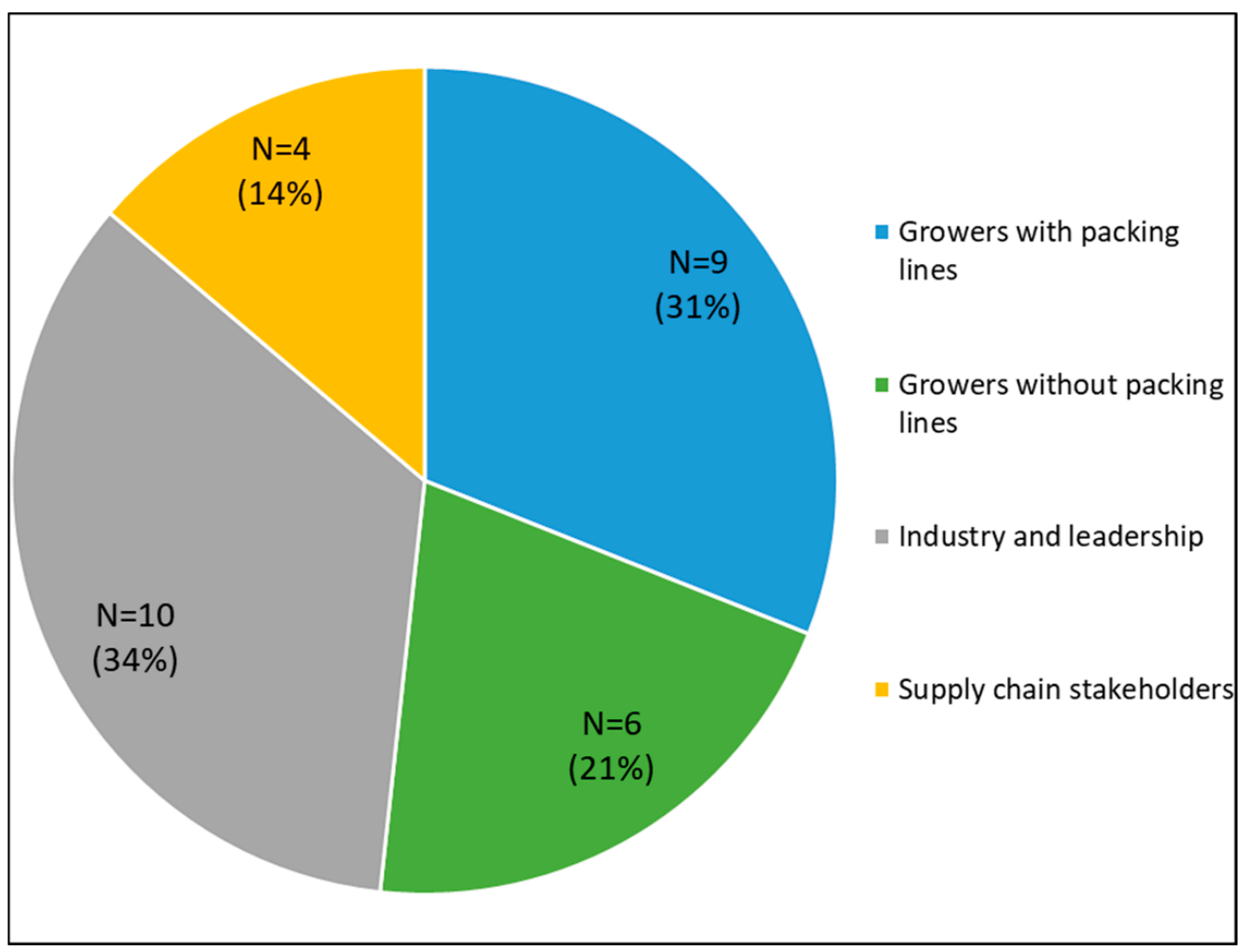

Figure 3. Distribution of stakeholder study participants.

\subsection{Stakeholder Views of Platform Features and Attributes}

Concerning stakeholder views of Sweet-APPS features and attributes (parameters \#1-13), participants generally found more value in having the ability to detect external sweetpotato characteristics compared to detecting internal characteristics or collecting 
information on environmental parameters (Figure 4A). For instance, one stakeholder said, "I like the idea of using more technology to gauge or determine things like size, shape, color ..." (Interviewee 10). They also found value in having the platform available through a smartphone, and there was some support to have a Spanish module on the user interface. Details are as follows, with supporting data shown in Tables S1-S3 in the SI.

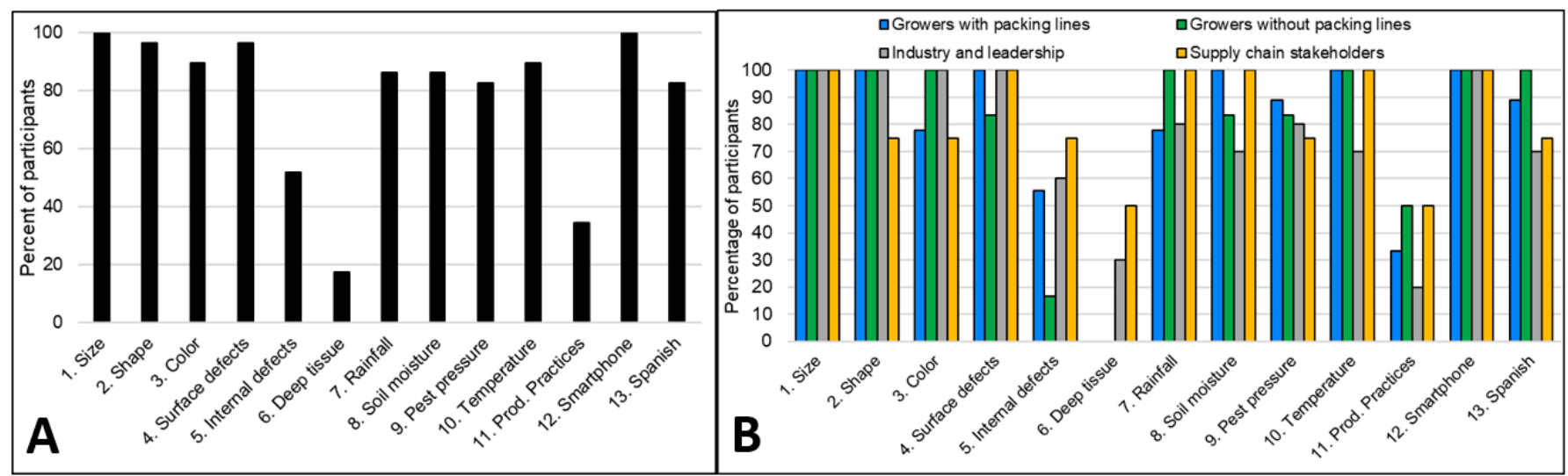

Figure 4. Stakeholder participant views of Sweet-APPS features and attributes according to perceived importance or value. Values shown in percentage of total participants. $(\mathbf{A})=$ all stakeholder groups; (B) $=$ findings across stakeholder groups.

All study participants (100\%) considered the ability to estimate sweetpotato size (\#1. Size) to be of high importance for inclusion in the Sweet-APPS platform (Figure 4A, Table S1 in SI). For example, one participant said the ability to quantify sweetpotato size was "Very important" (Interviewee 8). Similarly, all participants (100\%) indicated that the ability to use a smartphone, particularly in the field, rather than a desktop or laptop computer to use the platform would be of value (\#12. Smartphone), as exemplified by a participant who said, "I think something mobile, like a smart phone [would be of value]" (Interviewee 6). We also found that nearly all participants (i.e., 28 out of $29 ; 97 \%$ of participants) considered the ability to estimate sweetpotato shape and detect surface defects to be of high importance (\#2. Shape, 4. Surface defects). This was exemplified by one participant who said, "If we ... have potatoes all the same shape it would be a lot easier to deal with, for packaging and managing our inventory" (Interviewee 1). In addition, detecting SP color (\#3. Color) was also considered to be important according to $90 \%$ of study participants (i.e., 26 out of 29 participants), as exemplified by the following quote: "Shape or size, those are minimal problems for us. Surface defects peel off. Color; it would be color. Color would be the most [important]" (Interviewee 12). Further, more than $80 \%$ of study participants indicated that having a Spanish module would be of value (i.e., 24 participants; $83 \%$ ). Meanwhile, only half of study participants (i.e., $52 \%, 15$ out of 29 ) found value in the ability to detect internal defects (\#5. Internal defects), and only $17 \%$ of study participants (i.e., 5) were interested in the ability to detect deep tissue issues (\#6. Deep tissue) (Figure 4A, Table S1).

In terms of environmental parameters, $90 \%$ of study participants indicated that assessing temperature (\#10. Temperature) would be important (i.e., 26 out of 29 participants) for a variety of reasons (Table S2). For example, one respondent noted that, "when we have big fluctuations in temperature, or colder weather ... we have more of a skinning issue" (Interviewee 15), while another respondent indicated that "a stable ground temperature" was needed for cutting and transplanting slips (Interviewee 19). After temperature, rainfall and soil moisture (\#7 Rainfall, 8. Soil moisture) were deemed important by most participants (i.e., 86\%, 25 participants), followed by pest pressure (\#9. Pest pressure) (i.e., 83\%, 24 participants). As one interviewee said, "Rainfall would be super important" to include in Sweet-APPS (Interviewee 2), while another participant said "Pest pressure could easily jump to number one [priority], depending on the field" (Interviewee 12). When asked 
whether there were any other parameters that were important to quantify, one-third of participants (i.e., 34\%, 10 out of 29) mentioned that they found value in capturing agricultural production practices in the platform (\#11. Prod. Practices) (Figure 4A, Table S2).

When investigating these results across different stakeholder groups (Figure 4B), we found that there were similarities between stakeholders in regard to the importance of detecting sweetpotato size (\#1) and the option of using a smartphone for the platform (\#12), as all interviewees indicated these features to be of value. There was also agreement among most stakeholder groups in terms of the value of detecting surface defects (\#4) and temperature (\#10). At the same time, it was also clear that different stakeholders had different levels of interest in several parameters (Figure 4B). For example, supply chain stakeholders were less interested in the ability to capture sweetpotato shape (\#2), color (\#3), and pest pressure (\#9) compared to the other stakeholder groups, and rather more interested in detecting internal defects (\#5) and deep tissue (\#6) compared to the other groups. Industry and leadership participants also tended to be more interested in quantifying characteristics of sweetpotatoes (particularly \#1 Size, \#2 Shape, \#3 Color, and \#4 Surface defects, with some interest in detecting \#5 Internal defects and \#6 Deep tissue issues), and somewhat less interested in capturing various environmental parameters, including \#8 Soil moisture, \#10 Temperature, and \#11 Production practices. Industry and leadership were also the least interested in having a Spanish module compared to the other stakeholder groups (\#13. Spanish). For example, one industry participant indicated they would not be interested in a Spanish module, but "growers may" be interested (Interviewee 16). Growers with and without packing lines were also interested in some of the same parameters, such as quantifying sweetpotato size (\#1), shape (\#2), and temperature (\#10), although there were diverging interests in quantifying sweetpotato color (\#3) and surface defects (\#4), and particularly detecting internal defects (\#5) (with considerably less interest from growers without packing lines). These differences reported by different stakeholder groups are most likely attributed to the different needs and contexts in which different stakeholder groups operate, as expanded upon more in Section 4.

\subsection{Stakeholder Views of Data and Privacy Protection}

Regarding stakeholder views of data and user privacy protection, approximately two-thirds of participants (i.e., $69 \%, 20$ out of 29 ) indicated they thought it was important to have privacy and data protection for sweetpotato attributes (\#14. DP-SP key attribute; i.e., size, shape, color, surface defects) and production practices (\#16. DP-Prod. practices, such as application of fertilizers, pesticides, harvest time) in the platform (Figure 5A, Table S3). For example, when asked if Sweet-APPS should include information about production practices or inputs like their planting dates, harvest times, or fertilizers, one participant indicated that "Growers are pretty secretive sometimes of things that they do ... if they knew that other people could get that information, they may be less likely to enter it" (Interviewee 16). When asked the same question, another respondent said of those production practices that "a lot of guys consider that a 'special sauce' so yeah I could see everybody wanting to keep that private" (Interviewee 12). However, another respondent disagreed, not having "any concerns" about production practices because "everybody does about the same thing..." (Interviewee 15).

In contrast, less than half of participants (i.e., $41 \%, 12$ out of 29) felt it was important to have privacy and data protection for environmental parameters (\#15. DP-Environ. parameters, such as temperature, rainfall, soil moisture, pest pressure), as many of them indicated that these data were already publicly available for the most part. One stakeholder said that environmental parameters were not "a proprietary thing. And you can get data basically from the county. That's not something that's confidential anyway" (Interviewee 17). Relatively few participants felt it was important to have privacy and data protection on sweetpotato licensed algorithms generated by Sweet-APPS (\#17. DP-Algorithm) (i.e., $17 \%$, 5 out of 29), and only 4 participants (i.e., $14 \%$ ) were concerned with aggregating their data with other stakeholders and users (\#18. DP-Aggr. data). For example, one participant 
said, "as long as people are de-identified ... and anonymized ... the aggregate, getting the ... bigger picture is important, especially if it's going to be regional or by county ... that would be good, helpful information to know," and a second participant indicated being comfortable with "no access to the specifics but all access to the averages."

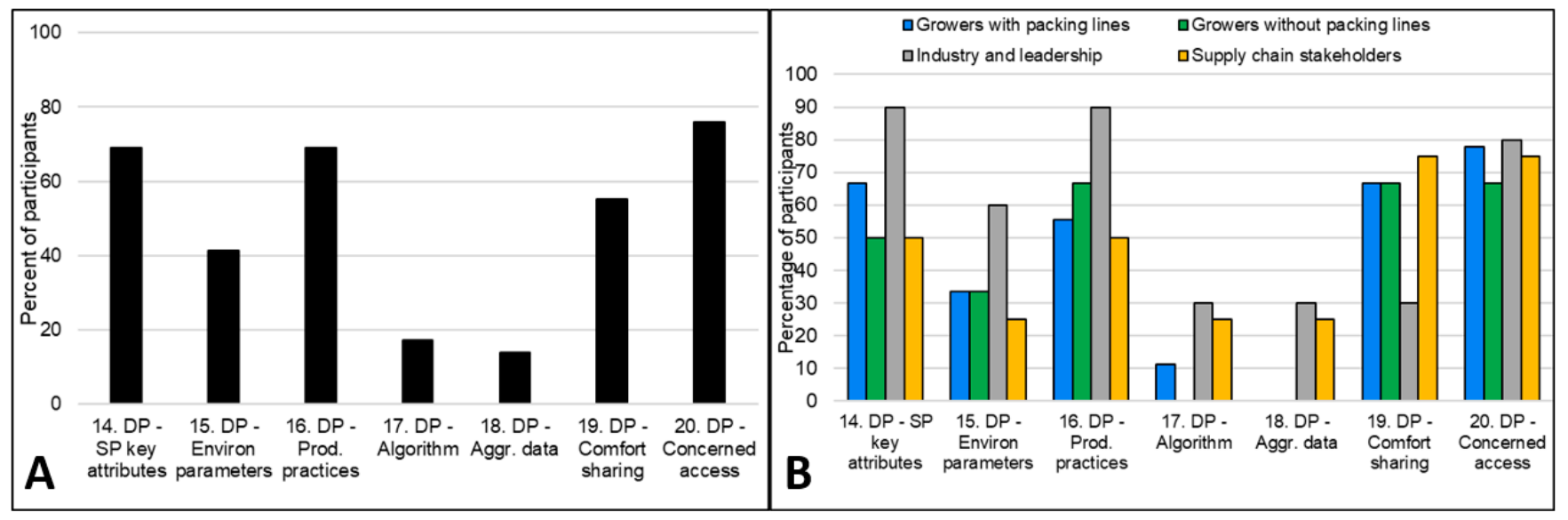

Figure 5. Stakeholder participant views of data and privacy protection relevant for Sweet-APPS platform, according to perceived importance or value. Values shown in percentage of total participants. $(\mathbf{A})=$ all stakeholder groups; $(\mathbf{B})=$ findings across stakeholder groups; $\mathrm{DP}=$ data and privacy.

Across the interview questions related to data privacy and protection, more than three-quarters of participants (i.e., 76\%, 22 out of 29) indicated they were concerned with who had access to data and information shared on the platform (\#20. DP-Concerned access) (Figure 5A, Table S3). For example, one participant said that the "data should be only available to the stakeholders, the ones who have a vested interest. We don't want ... our information out there for everybody" (Interviewee 1). Another participant mentioned they would be concerned with sharing data with competitors: "The biggest concern for me is your competitors, whether that competitor is your next-door neighbor or its competitors out of state or out of the country; that is the biggest one that you want to keep-I mean any of our competitors we don't want" (Interviewee 5). Relatedly, only a little more than half of participants (i.e., $55 \%, 16$ out of 29 ) indicated they were comfortable sharing their data with other stakeholders and users (\#19. DP-Comfort sharing). As one participant noted, "as long as I have control over who sees the data. I mean, I wouldn't want to put it on a public platform, so to speak, where anyone can go to it and look at it without my approval or whoever owns that data. I think each individual farmer, or whoever it is, should have control over who's looking at the data" (Interviewee 3).

Building off this theme, we also found that several study participants indicated they were more comfortable with sharing data/information with other stakeholders in North Carolina, but were hesitant to share outside of North Carolina. For example, when asked who they may be most concerned about accessing Sweet-APPS data and information, one participant noted " ... competitive states ... That would be the only thing, our competitive states. We don't want-we already flood the market our self, bad enough" (Interviewee 5). Another participant mentioned competitive concerns and the need to support the local industry in North Carolina: " . . the industry in itself, the board, gets a lot of pressure from the growers to make sure that North Carolina growers are taken care of and our growers are helped first if they're the ones that are funding it or we are the ones that are helping out with it or stuff like that. So, yeah, I mean there's some concern about the program, yeah" (Interviewee 8).

When viewing these findings across stakeholder groups, there were some similarities and differences between groups regarding perceptions of data and privacy protection needs. There was most alignment between stakeholder groups in terms of having some concerns over who had access to data in Sweet-APPS (\#20. DP-Concerned access) (Figure 5B, 
Table S3). For example, more than three-quarters of all participants from industry and leadership (i.e., $80 \%$ of industry and leadership stakeholders, $n=8$ ), growers with packing lines $(78 \%, n=7)$, and supply chain stakeholders $(75 \%, n=3)$ expressed concern with who had access to data in the Sweet-APPS platform. For example, when asked if they were concerned about sharing data, one participant from industry and leadership said they would be concerned with " ... the growers ... [in] other states and other countries. They would not want to see that outside of this area, especially now I guess, Europe, right, cause that's going to become a major competitor here in the next five years" (Interviewee 23).

Stakeholders from industry and leadership were also most concerned over data and privacy issues as they related to most Sweet-APPS features (Figure 5B). For example, they were the most concerned over protecting sweetpotato features (\#14. DP-SP key attributes), environmental parameters (\#15. DP-Environ. parameters), and production practices (\#16. DP-Prod. practices). They were also the most concerned about privacy and data protection for licensed algorithms (\#17. DP-Algorithm) and concerns about aggregating data and information with other stakeholders (\#18. DP-Aggr. data). At the same time, the supply chain stakeholders had the least amount of concerns regarding data and privacy issues across several Sweet-APPS features, particularly concerns related to environmental parameters (\#15. DP-Environ. parameters) and production practices (\#16. DP-Prod. practices). Growers with and without packing line were generally not concerned with data and privacy issues as they related to sweetpotato licensed algorithms (\#17. DP-Algorithm) and aggregating data and information with other stakeholders (\#18. DP-Aggr. data). Similar to findings reported on stakeholder perceived value of SweetAPPS features and attributes, these findings from different stakeholder groups may be attributed to the different needs and contexts in which they may operate, as discussed in the subsequent sections.

\subsection{Study Limitations}

In addition to reporting the results of our study, we also acknowledge that our approach may have several limitations. First, this study reports on findings from individual interviews with 29 stakeholders associated with the North Carolina sweetpotato value chain. Due to the small sample size, it was not scientifically sound to perform statistical analyses across stakeholder groups to assess how their responses statistically differed between and across groups. Further, this study did not aim to include other stakeholders outside of the sweetpotato value chain, such as environmental nongovernmental organizations (NGOs), consumer advocacy groups, regulators and policymakers, given our focus on understanding views and priorities related to the sensing and data analytics platform developed in Sweet-APS. While we recognize the small number of study participants, we feel that the study design and conduction was effective to identify key priorities, needs, and concerns of the greater North Carolina sweetpotato community as related to a sensing and diagnostic platform. Second, we realize that there were several technical terms included in the interview protocol (e.g., "diagnostic sensing and data platform," "user interface," "cloud data service provider"), and not all study participants may have been intimately familiar with these terms. In response, we provided explanations of these terms in a copy of the interview questions, and the interviewee explained what these terms meant during the interviews. Third, we conducted our study over virtual meeting and/or phone in light of the COVID-19 pandemic, in which in-person interviews were not possible. We recognize that in-person interviews and interactions are advantageous in terms of creating a connection between study participant(s) and interviewee(s), although we felt that many study participants were already quite familiar with virtual/remote communication when we conducted the study.

\section{Discussion}

This study conducted interviews with 29 stakeholders associated with the North Carolina sweetpotato value chain to identify their needs, preferences, and concerns as they 
relate to developing a new sensing and diagnostic platform tailored for sweetpotatoes. Our approach to engaging, eliciting, and then incorporating stakeholder perspectives in technology development and design processes adheres to the RI pillar of inclusion [9]. Through the conduction of stakeholder interviews, we also identified five main themes that emerged. First, participants generally found more value in having the ability to detect external characteristics of sweetpotatoes compared to detecting internal characteristics or collecting information about environmental parameters. Participants were most interested in quantifying sweetpotato size, closely followed by shape and surface defects, and then color. About half of the participants found value in detecting internal defects, and a few participants were interested in being able to conduct deep tissue analyses (with most support within supply chain and industry/leadership groups). Overall, these findings support the idea that new agrifood technologies to assess and estimate (external) sweetpotato characteristics would be of value to North Carolina sweetpotato stakeholders, especially given that current approaches often rely on manual inspection of size, shape, and other features. Having more consistent and accurate estimates of sweetpotato characteristics can assist in better estimates of crop yields, and thereby improve market values as they relate to sweetpotato production, processing, packing, and distribution. These findings also reveal some differences between stakeholder groups, in terms of the sensing and diagnostic platform features they found value in, as highlighted below.

Second, participants indicated interest in including and quantifying various environmental factors, albeit less so than quantifying external sweetpotato characteristics. Across a range of environmental parameters, participants found most value in integrating parameters of temperature, followed closely by rainfall and soil moisture in the Sweet-APPS platform. This was followed by support to include pest pressure, and then agricultural production practices. Many study participants indicated that while including environmental factors would be of value to them, these data and information are for the most part already publicly available and therefore not considered essential for inclusion in the Sweet-APPS platform. Third, all stakeholders expressed support of using or connecting to a smartphone rather than only using a desktop or laptop computer to use the platform. Many participants indicated that this would be of value to them, as they could use it in the field, and therefore it would provide a substantial improvement over existing technologies. Further, most participants found value in including a Spanish language module (particularly the growers with and without the packing lines). These findings reveal the larger contextual circumstances of sweetpotato stakeholders in North Carolina, in terms of adapting to new communication technologies that allow for better flexibility and access in the field, as well as changing socio-economic conditions within the state, with many agricultural workers speaking Spanish.

Fourth, most stakeholders indicated support for having privacy and data protection in the Sweet-APPS platform, particularly to protect data from potential competitors. In fact, this was one of the most interesting and surprising findings that arose from the interviews, in that study participants indicated that they would be supportive of sharing data with other stakeholders as long as they were not "outside" competitors and sharing the data would support the greater North Carolina sweetpotato industry. Following concerns over who had access to Sweet-APPS data, most study participants indicated that they thought data and privacy protection was needed to protect data related to sweetpotato attributes and agricultural production practices. Further, less than half of participants were concerned with protecting information related to environmental parameters, and relatively few participants felt privacy and data protection on sweetpotato licensed algorithms were needed. Similarly, relatively few participants indicated concern with aggregating their data with other stakeholders. Overall, these findings reveal an interesting pattern, in that participants' indicated their comfort with sharing data and information as long as it benefits the greater North Carolina sweetpotato industry, and were concerned with sharing these data (particularly related to sweetpotato attributes and agricultural production practices) with "outside" competitors. Therefore, there was a notable tension between the sense 
of contributing to a larger community while also protecting market competition, framed within the context of data access and sharing.

Fifth, there were differences and variations in responses between stakeholder groups. Many of these differences were likely attributed to the different needs and contexts in which the stakeholders operate. For example, supply chain and industry/leadership stakeholders were most interested in having the ability to detect internal defects and conduct deep tissue analyses-most likely because they are stakeholders involved in the storing, delivering, and marketing of sweetpotatoes and would be affected by internal issues that are difficult to detect on the surface (e.g., internal necrosis). Further, the growers with and without packing lines indicated support of having a Spanish module in the platform, with less support from industry/leadership and supply chain stakeholders. This is also likely due to the fact that growers often use Spanish-speaking agricultural workers in the fields, and therefore having a Spanish module would be more important for them. These findings reveal that different stakeholders have different needs, priorities, and concerns, and these most likely are linked to their contexts within the greater sweetpotato industry.

Following the best practices of RI, these five themes will be incorporated back into the next phase of technology development in the Sweet-APPS project, corresponding to the RI pillar of responsiveness [9]. By having a clearer understanding of stakeholders' priorities, needs, and concerns related to the sensing and diagnostic platform, we will, for instance, prioritize some key features of Sweet-APPS over others in the next development phase. This includes pursuing technologies to estimate sweetpotato size, shape, surface defects, and color, in addition to exploring options for use on a smartphone for in-field use, with a Spanish module, and ensuring adequate data and privacy protection for users. This work also revealed that different stakeholders have different needs in regards to platform features, and in some cases, trade-offs between features may be necessary in subsequent versions of the platform.

Finally, this work demonstrates an example of conducting real-time technology assessment within a local, agricultural context to develop new technologies, with the overall goal of improving sustainability within an agrifood industry. In this work, a better understanding of key parameters that influence sweetpotato yield will lead to reduced agricultural food waste and improved sustainability and respond to needs within the sweetpotato community. In addition, we found value in being as adaptive as possible to respond to stakeholder preferences to carry out the study, such as transitioning to virtual and/or phone-based meeting platforms in the midst of a pandemic in which in-person meetings were limited. In this process, we found value in working with individual stakeholder participants to identify the best mechanism as well as time to conduct the interviews, as well as to follow up with any additional questions they had with regard to the Sweet-APPS project. This ability to be responsive and adaptive to study participant needs will likely be very relevant for future studies as well, especially as our society continues to move towards more remote and virtual communication formats. Overall, this study also demonstrates a relatively simple, straight-forward, and low-cost approach to eliciting stakeholder needs within a local agricultural context, through tapping into already-established networks of agricultural community members to set up engagement mechanisms in a way that best meets stakeholder needs, an approach that could be leveraged and transferred to other local agrifood systems.

\section{Conclusions}

This paper reports on the process used to identify stakeholder needs, preferences, and concerns as they relate to developing a new sensing and diagnostic platform through the Sweet-APPS project, relevant for the North Carolina sweetpotato industry. Through the conduction of 29 interviews with stakeholders between December 2020 and June 2021, we found that new agrifood technologies to assess and estimate sweetpotato (external) characteristics would be of value to North Carolina sweetpotato stakeholders, particularly with an in-field smartphone option. We also found that participants expressed interest 
in including and quantifying various environmental factors in the platform (particularly temperature, rainfall, and soil moisture) and having a Spanish module (particularly for growers). Stakeholders also indicated that they would be supportive of sharing data with others within the greater North Carolina sweetpotato community but were skeptical of sharing with outside competitors. We also found that different stakeholders have different needs in regards to platform features, and in some cases, trade-offs between features may be necessary in subsequent versions of the platform. This study also demonstrates a simple, straightforward, and low-cost approach to eliciting stakeholder needs within a local agricultural context that could be leveraged and transferred to other local agrifood systems.

Supplementary Materials: The following are available online at https:/ / www.mdpi.com/article / 10.3390/su14042274/s1, Interview Guide for Study Participants; Results from Stakeholder Interviews: Table S1. Stakeholder participant views of Sweet-APPS sweet potato features and attributes according to perceived im-portance or value. Values shown in both total number and percentage of total participants across stakeholder groups; Table S2. Stakeholder participant views of SweetAPPS environmental pa-rameter and user interface features and attributes according to perceived importance or value. Values shown in both total number and percentage of total participants across stakeholder groups; Table S3. Stakeholder participant views of data and privacy protection relevant for Sweet-APPS platform. Values shown in both total number and percentage of total participants across stake-holder groups.

Author Contributions: Conceptualization, K.G. and J.K.; formal analysis, K.G. and S.Z.; funding acquisition, J.K.; investigation, K.G., S.Z., S.K.B.-D., S.H. and D.J.; methodology, K.G., S.Z. and J.K.; project administration, K.G.; software, S.K.B.-D.; supervision, K.G. and D.J.; visualization, K.G.; writing—original draft, K.G., S.Z., D.J. and J.K.; writing-review and editing, K.G., S.Z., S.K.B.-D., S.H., D.J. and J.K. All authors have read and agreed to the published version of the manuscript.

Funding: This study was funded through a North Carolina State University seed grant through grant number 573000, termed "Sweetpotato Analytics for Produce Provenance and Scanning" (Sweet-APPS) (PI = Cranos Williams). We also acknowledge the partial funding support provided by the Genetic Engineering and Society Center and Cooperative Extension Program at NC State.

Institutional Review Board Statement: This study received Institutional Review Board (IRB) approval for the use of human subjects in research from the PI's institute, North Carolina State University, Protocol Number 22347.

Informed Consent Statement: Informed consent was obtained from all subjects involved in the study.

Data Availability Statement: All data supporting reported results are available in the Supplementary Information.

Acknowledgments: We also acknowledge the contributions made by several individuals towards the conduction of the study: Sharon Stauffer and Emily Gentherfrom NC State University, as well as Michelle Grainger from the North Carolina SweetPotato Commission. We would also thank the rest of the Sweet-APPS team, including the PI Cranos Williams, and co-PIs Michael Kudenov, Craig Yencho, and Mike Boyette.

Conflicts of Interest: The authors declare no conflict of interest.

\section{References}

1. Kliskey, A.; Williams, P.; Griffith, D.L.; Dale, V.H.; Schelly, C.; Marshall, A.-M.; Gagnon, V.S.; Eaton, W.M.; Floress, K. Thinking Big and Thinking Small: A Conceptual Framework for Best Practices in Community and Stakeholder Engagement in Food, Energy, and Water Systems. Sustainability 2021, 13, 2160. [CrossRef]

2. Beland Lindahl, K.; Baker, S.; Rist, L.; Zachrisson, A. Theorising Pathways to Sustainability. Int. J. Sustain. Dev. World Ecol. 2016, 23, 399-411. [CrossRef]

3. Leach, M.; Stirling, A.C.; Scoones, I. Dynamic Sustainabilities: Technology, Environment, Social Justice; Routledge: London, UK, 2010; ISBN 978-1-84977-506-9.

4. Ely, A.; Van Zwanenberg, P.; Stirling, A. Broadening out and Opening up Technology Assessment: Approaches to Enhance International Development, Co-Ordination and Democratisation. Res. Policy 2014, 43, 505-518. [CrossRef]

5. Guston, D.H.; Sarewitz, D. Real-Time Technology Assessment. Technol. Soc. 2002, 24, 93-109. [CrossRef]

6. Schot, J. Towards New Forms of Participatory Technology Development. Technol. Anal. Strateg. Manag. 2001, 13, 39-52. [CrossRef] 
7. Rodemeyer, M.; Sarewitz, D.; Wilsdon, J. The Future of Technology Assessment; Woodrow Wilson International Center for Scholars: Washington DC, USA, 2005; pp. 1-29. Available online: https://www.wilsoncenter.org/sites/default/files/media/documents/ publication/techassessment.pdf (accessed on 12 February 2022).

8. Felt, U. Responsible Research and Innovation. In Handbook of Genomics, Health and Society; Routledge: New York, NY, USA, 2018; ISBN 978-1-315-45169-5.

9. Stilgoe, J.; Owen, R.; Macnaghten, P. Developing a Framework for Responsible Innovation. Res. Policy 2013, 42, 1568-1580. [CrossRef]

10. Burget, M.; Bardone, E.; Pedaste, M. Definitions and Conceptual Dimensions of Responsible Research and Innovation: A Literature Review. Sci. Eng. Ethics 2017, 23, 1-19. [CrossRef] [PubMed]

11. Von Schomberg, R. Towards Responsible Research and Innovation in the Information and Communication Technologies and Security Technologies Fields; Social Science Research Network: Rochester, NY, USA, 2011.

12. Chambers, R. Participatory Rural Appraisal (PRA): Analysis of Experience. World Dev. 1994, 22, 1253-1268. [CrossRef]

13. Govaerts, B.; Negra, C.; Villa, T.C.C.; Suarez, X.C.; Espinosa, A.D.; Fonteyne, S.; Gardeazabal, A.; Gonzalez, G.; Singh, R.G.; Kommerell, V.; et al. One CGIAR and the Integrated Agri-Food Systems Initiative: From Short-Termism to Transformation of the World's Food Systems. PLoS ONE 2021, 16, e0252832. [CrossRef] [PubMed]

14. USDA National Agricultural Statistics Service. NASS-Quick Stats, Ag Data Commons. 2017. Available online: https://data.nal. usda.gov/dataset/nass-quick-stats (accessed on 13 December 2021).

15. Loebenstein, G. Chapter Two-Control of Sweet Potato Virus Diseases. In Advances in Virus Research; Loebenstein, G., Katis, N.I., Eds.; Control of Plant Virus Diseases; Academic Press: Cambridge, MA, USA, 2015; Volume 91, pp. $33-45$.

16. Gething, K.; Henderson, C.; McIntyre, A.; Dennien, S. Sweetpotato Consumer Research: Insights to Increasing Consumption; Technical Report 2012; Queensland Government: Brisbane, Australia, 2012. Available online: http://era.daf.qld.gov.au/id/eprint/3572/ (accessed on 13 December 2021).

17. United States Department of Agriculture; Agricultural Marketing Service. United States Standards for Grades of Sweet Potatoes; Document Doc. No. FV-04-302; Agricultural Marketing Service: Washington, DC, USA, 2005. Available online: https://www. federalregister.gov / documents /2005/03/22/05-5608/united-states-standards-for-grades-of-sweet-potatoes (accessed on 13 December 2021).

18. Food and Agriculture Organization of the United Nations. Moving Forward on Food Loss and Waste Reduction; FAO, Ed.; The State of Food and Agriculture: Rome, Italy, 2019; ISBN 978-92-5-131789-1.

19. Weber, C.T.; Trierweiler, L.F.; Trierweiler, J.O. Food Waste Biorefinery Advocating Circular Economy: Bioethanol and Distilled Beverage from Sweet Potato. J. Clean. Prod. 2020, 268, 121788. [CrossRef] 